\title{
An Epidemic in Evolution: The Need for New Models of HIV Care in the Chronic Disease Era
}

\author{
Carolyn Chu and Peter A. Selwyn
}

\begin{abstract}
Since the beginning of the AIDS epidemic, models of HIV care have needed to be invented or modified as the needs of patients and communities evolved. Early in the epidemic, primary care and palliative care predominated; subsequently, the emergence of effective therapy for HIV infection led to further specialization and a focus on increasingly complex antiretroviral therapy as the cornerstone of effective HIV care. Over the past decade, factors including (1) an aging, long-surviving population; (2) multiple co-morbidities; (3) polypharmacy; and (4) the need for chronic disease management have led to a need for further evolution of HIV care models. Moreover, geographic diffusion; persistent disparities in timely HIV diagnosis, treatment access, and outcomes; and the aging of the HIV provider workforce also suggest the importance of reincorporating primary care providers into the spectrum of HIV care in the current era. Although some HIV-dedicated treatment centers offer comprehensive medical services, other models of HIV care potentially exist and should be developed and evaluated. In particular, primary care- and community-based collaborative practices-where HIV experts or specialists are incorporated into existing health centers-are one approach that combines the benefits of HIV-specific expertise and comprehensive primary care using an integrated, patient-centered approach.
\end{abstract}

KEYWORDS HIV primary care, HIV health services, HIV care models

\section{BACKGROUND}

HIV infection has evolved into a chronic disease with effective combination antiretroviral therapy. Meanwhile, new infections continue to occur in every region, age range, and ethnic group in the United States. ${ }^{1,2}$ As the HIV-positive population grows, so do its healthcare needs-especially with aging and the development of other chronic complications and co-morbidities. HIV care must, therefore, go beyond an antiretroviral-focused approach to one which addresses the heterogeneous and complex elements of long-term infection, chronic disease management, increasing polypharmacy, and other patient- and population-specific factors. Central to this paradigm shift is the recognition that primary care* will be increasingly important in the current treatment era, much as it was during the early years of the epidemic (Figure 1). ${ }^{4}$

\footnotetext{
"The Institute of Medicine defines primary care as the provision of "integrated, accessible health services by clinicians accountable for addressing a large majority of personal health needs." 3

Chu and Selwyn are with the Department of Family and Social Medicine, Montefiore Medical Center/ Albert Einstein College of Medicine, Bronx, NY, United States.

Correspondence: Carolyn Chu, Department of Family and Social Medicine, Montefiore Medical Center/Albert Einstein College of Medicine, Bronx, NY, United States. (E-mail: cchu@montefiore.org)
} 


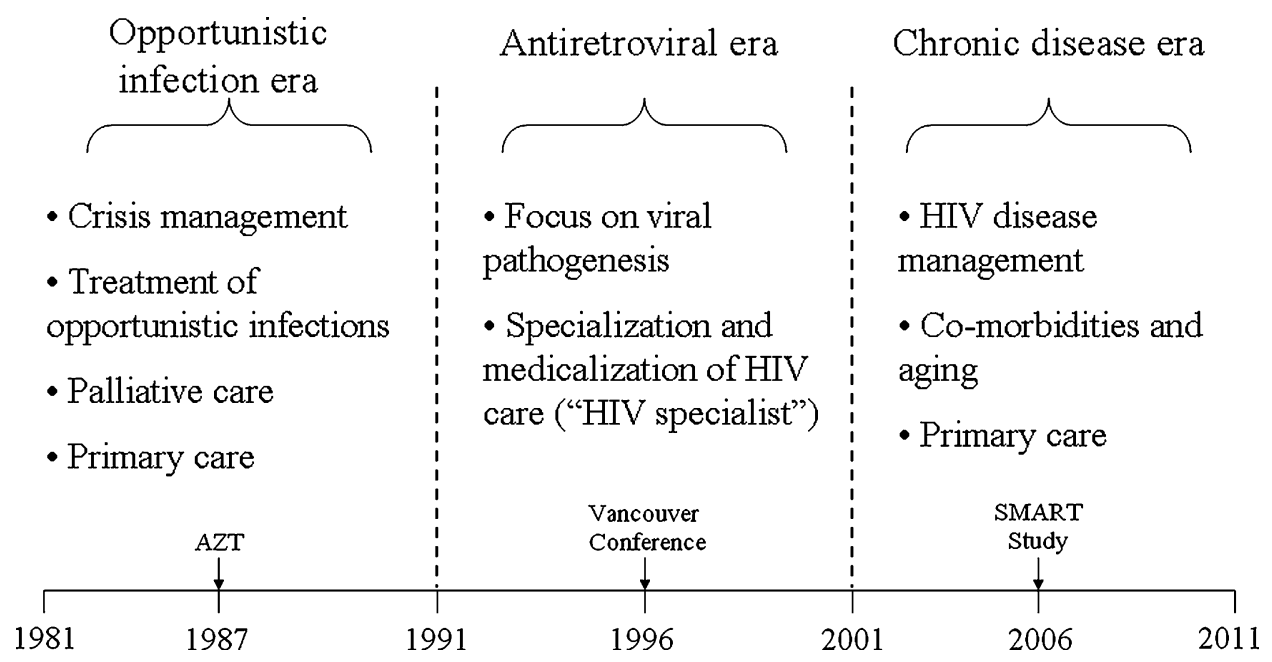

FIGURE 1. The HIV/AIDS epidemic: major clinical themes over 3 distinct eras, 1981-2011.

Research among patients with AIDS in the Highly Active Antiretroviral Therapy (HAART) era demonstrated that primary care delivery was associated with improved survival; ${ }^{5}$ this will undoubtedly be amplified in the decades ahead as chronic disease management becomes a larger issue for the HIV-positive population. ${ }^{6}$ Moreover, primary care providers-who comprise the infrastructure of community-based, firstcontact care - can play a significant role in public health efforts to identify infected patients early and link them into timely care and HIV treatment. This is especially important for 2 reasons: late diagnosis and under-diagnosis of HIV are concentrated in racial-ethnic minorities, the elderly, and other potentially vulnerable populations; ${ }^{1}$ and the estimated one quarter of infected patients who are unaware of their status are believed to account for $50-70 \%$ of new (sexually acquired) infections. ${ }^{7,8}$ However, much is unknown about current HIV care delivery, namely: (1) whether and how HIV providers are meeting patients' primary care needs; and (2) how structures and models of care can be improved to combine HIV-specific expertise with comprehensiveness, continuity, coordination, and accessibility—four key elements of primary care.

\section{CHANGING PATIENTS: MORBIDITY, MORTALITY, AND AGING}

Coincident with improved survival, patterns of co-morbidity and mortality have changed among HIV-positive patients: cardiovascular disease, hypertension, and diabetes have become prevalent, ${ }^{9-11}$ and causes of death have shifted from opportunistic infections to end-stage liver and kidney disease and non-HIV-related malignancies (Table 1). ${ }^{12-14}$ Research also shows that HIV infection directly affects other organ systems, manifesting as chronic conditions including HIV-associated neurocognitive disorder and pulmonary hypertension. Such findings have important implications for clinicians caring for HIV-infected patients, as the co-management of HIV and other diseases may be complicated by issues such as polypharmacy and medication-associated toxicities-highlighting the need for comprehensive, coordinated care.

Aging of the HIV-positive population is also raising new concerns, as (1) individuals 40 years old and over make up approximately $75 \%$ of the population 
TABLE 1 Changes in mortality and peri-mortal conditions among decedents with HIV in the pre-highly active antiretroviral therapy (pre-HAART) versus HAART eras, 1992-2003 (Adult/ Adolescent Spectrum of HIV Disease Project) ${ }^{9}$

\begin{tabular}{|c|c|c|c|}
\hline $\begin{array}{l}\text { Increasing linear trends, } \\
\text { pre-HAART vs. HAART era }\end{array}$ & $\begin{array}{l}\text { Adjusted odds } \\
\text { ratio }\end{array}$ & $\begin{array}{l}\text { Decreasing linear trends, } \\
\text { pre-HAART vs. HAART era }\end{array}$ & Adjusted odds ratio \\
\hline Septicemia & 1.12 & $\begin{array}{l}\text { Non-tuberculous } \\
\text { mycobacterial disease }\end{array}$ & 0.55 \\
\hline Kidney disease & 1.22 & Kaposi sarcoma & 0.65 \\
\hline $\begin{array}{l}\text { Liver disease } \\
\text { (excluding viral hepatitis) }\end{array}$ & 1.50 & Cytomegalovirus disease & 0.65 \\
\hline Viral hepatitis & 3.27 & Pneumocystosis & 0.77 \\
\hline Gastrointestinal hemorrhage & 1.26 & Dementia & 0.70 \\
\hline Ischemic heart disease & 1.57 & Toxoplasmosis & 0.72 \\
\hline Alcohol abuse & 1.81 & Anemia & 0.74 \\
\hline Hypertensive disease & 1.88 & Tuberculosis & 0.77 \\
\hline Diabetes mellitus & 1.58 & Coccidiosis or isosporiasis & 0.48 \\
\hline
\end{tabular}

living with HIV in the United States and (2) new diagnoses are still occurring in older patients. ${ }^{1}$ Life expectancy has improved markedly, and the ambulatory care of infected patients now potentially spans several decades-underscoring the importance of continuity, longitudinal care, and awareness of aging-related issues. Older patients are at high risk for socioeconomic stressors, including unstable employment, financial strain, and isolation (all of which are barriers to accessing appropriate care). ${ }^{15}$ Multiple co-morbidities and aging-related processes such as worsening immune function, sensorineural impairment, gait instability, and general functional decline may also lead to frailty and disability among older HIV-positive adults. $^{16-19}$ Multi-disciplinary teams-already in place at many HIV treatment centers-may, therefore, need to expand and include specifically trained professionals to address patients' functional and home-care needs, and to provide outreach to engage (or reengage) patients. Also, community-based and primary care providers are strategically located to help implement expanded HIV testing and education programs to raise HIV/AIDS awareness among older adults. This is particularly important since older infected patients tend to be identified late, with lower CD4 counts and higher rates of AIDS at time of HIV diagnosis. ${ }^{20,21}$ All of these factors highlight the growing and complex trajectory of HIV and its related disease burden, which subsequently raise new challenges for health providers and systems alike.

\section{CHANGING PROVIDERS: NEW RESPONSIBILITIES, IMPENDING SHORTAGES}

As noted above, HIV care now includes the coordinated treatment of multiple chronic co-morbidities in a changing population. However, disease management for many patients has become highly specialized and antiretroviral-focused, partly in response to the increasing complexity and rapid evolution of HIV-specific therapies. Nevertheless, it is important that all current and future HIV providers build their fund of primary care-related knowledge and skills (for example, through continuous medical education) and HIV-dedicated centers and programs integrate primary medical care into their services. Additionally, primary care- and generalist-trained clinicians may need to bring HIV-infected patients back into their practices given the 
large numbers of infected patients needing care and treatment. Research shows that HIV providers (both infectious disease specialists and general medicine-certified physicians working at infectious disease clinics) are less comfortable treating hyperlipidemia, diabetes, hypertension, and depression compared to providers at general medicine clinics. ${ }^{22}$ High-volume and/or over-paneled HIV providers also refer patients for management of these co-morbidities more often and discuss condom use and transmission risk reduction less consistently; ${ }^{23}$ such practice patterns likely reflect multiple issues, including time constraints and competing demands, and possibly provider experience and/or comfort. Finally, data suggest that some HIV-infected patients are not receiving routine health maintenance services (e.g., mammography and colorectal cancer screening). ${ }^{24,25}$ Therefore, most if not all HIV-infected patients will benefit from a clinician-either their HIV provider (who may be a specialist or generalist by training) or another clinicianwho can assume the primary care provider (PCP) role to manage common comorbidities, coordinate treatment, and ensure that prevention and health maintenance are addressed, in addition to the necessity for HIV-specific expertise.

Although the evidence above indicates HIV providers will have increasing responsibilities in the years to come, the effective delivery of comprehensive care to a growing HIV-infected population may be difficult given predicted physician shortages. $^{26}$ In a 2008 American Academy of HIV Medicine (AAHIVM) survey distributed to a cohort of HIV experts, approximately one third of current providers-mostly representing the first generation of HIV clinicians cropping up in the mid to late 1980 s with the start of the epidemic-reported that they plan to retire over the next 10 to 15 years. ${ }^{27}$ However, over $90 \%$ of them noted an increase in their HIV patient load in the previous 2 years. Results of the 2010 HealthHIV State of HIV Primary Care survey further demonstrated that almost $80 \%$ of HIV specialists carry an annual caseload of over $200 \mathrm{HIV}$-positive patients in their practice or organization. ${ }^{28}$ Such findings emphasize the need to recruit more clinicians and clinicians-in-training into HIV care. Particularly for non-subspecialtytrained providers, this will require the accumulation of sufficient HIV management experience (arguably the most important predictor of effective HIV care) and ongoing HIV-related education. Alternatively, other practice models could be developed to directly link non-HIV-expert PCPs to on-site or local, qualified HIV experts or specialists. Current data suggest that generalists are unevenly represented across the population of HIV providers, a group which is also mostly male and white (Table 2). In response, several organizations (e.g., AAHIVM, HIV Medicine Association, the AIDS Education and Training Centers Program of the Ryan White CARE Act, HealthHIV) have increased their efforts to: (1) draw students and clinicians into HIV medicine and increase provider diversity, (2) advocate for HIVrelated loan repayment programs and provider reimbursement changes, and (3) provide up-to-date clinical training for primary care providers. Finally, the geographic distribution of clinicians must also change in response to the evolving epidemic as infections continue to increase in medically underserved rural and innercity areas and the South (Figure 2)—regions where patients often delay care ${ }^{32-34}$ and HIV treatment centers have difficulty recruiting and retaining providers. ${ }^{27}$

\footnotetext{
*Some studies have found that provider gender and race affect patient satisfaction and health service utilization. $^{29-31}$
} 
TABLE 2 Characteristics of HIV specialists: HIV Medicine Association (HIVMA) and American Academy of HIV Medicine memberships (AAHIVM), 2009

\begin{tabular}{|c|c|c|c|}
\hline & & HIVMA $n=3794(\%)$ & AAHIVM $n=1164(\%)$ \\
\hline \multirow[t]{2}{*}{ Gender } & Male & 67 & 60 \\
\hline & Female & 33 & 40 \\
\hline \multirow[t]{2}{*}{ Race } & White & 63 & 69 \\
\hline & Non-white & 37 & 31 \\
\hline \multirow[t]{4}{*}{ Training } & Infectious Diseases & 86 & 32 \\
\hline & General Internal Medicine & 9 & 33 \\
\hline & Family Medicine & 1 & 25 \\
\hline & Other & 4 & 10 \\
\hline \multicolumn{2}{|c|}{$\geq 50$ years of age ${ }^{a}$} & 40 & 44 \\
\hline \multirow[t]{4}{*}{ Region } & Northeast & 38 & 36 \\
\hline & Southeast & 25 & 19 \\
\hline & Midwest & 19 & 16 \\
\hline & West & 17 & 29 \\
\hline
\end{tabular}

Source: A. Weddle (HIVMA) 7/09, K. South (AAHIVM) 9/09 (personal communication)

${ }^{a}$ Or self-reported $\leq 15$ years to retirement

\section{HIV-RELATED HEALTH DISPARITIES}

With the increasing ratio of patients to providers, current HIV disparitiesespecially those involving access to care and treatment-will likely worsen. The geographic disparities mentioned above overlap with underlying socioeconomic and racial inequalities driving the US epidemic: for example, poorer communities have higher rates of HIV/AIDS and patients with low socioeconomic status have lower survival rates; ${ }^{35-38}$ patients without adequate insurance are less likely to be on antiretroviral therapy; ${ }^{39}$ substance users and minorities are more likely to delay

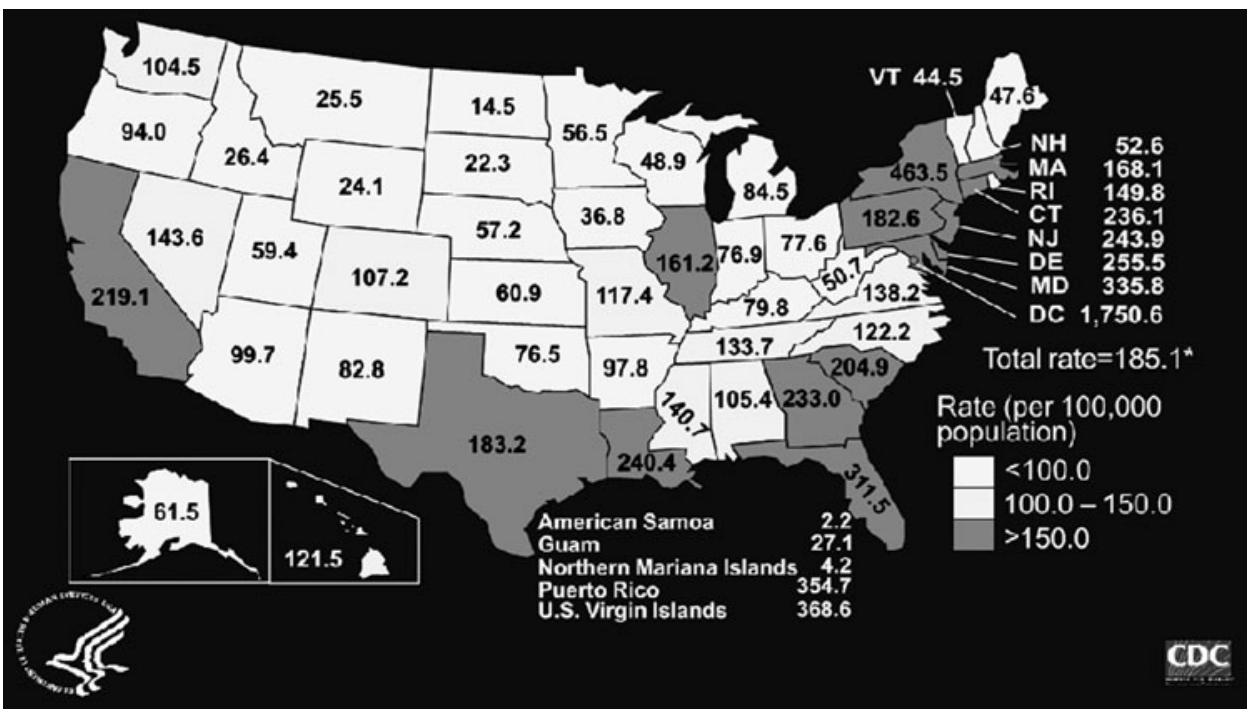

FIGURE 2. Estimated prevalence rates for adults and adolescents living with AIDS (per 100,000 population) in the United States and dependent areas, 2007. Source: Centers for Disease Control and Prevention. ${ }^{1}$ Data have been adjusted for reporting delays. ${ }^{*}$ Total rate includes persons whose area of residence is unknown or missing. 
medical care; ${ }^{40,41}$ and minorities (continue to) experience higher death rates, even after the introduction of combination therapy. ${ }^{42}$ Finally, HIV-infected patients who are homeless or unstably housed (usually as a result of poverty, mental illness, and/ or substance use) often do not have a regular source of care and are less likely to receive and stay on antiretroviral therapy. ${ }^{43}$ To complement clinician-based changes such as those suggested previously, primary care networks can help improve access to HIV treatment and reduce important health disparities by implementing systemsbased strategies (e.g., community-based HIV service programs) to provide appropriate care. These programs may be especially valuable for patients who cannot easily travel to specialty centers as well as vulnerable and medically underserved groups. Primary care and community-based HIV services may also connect with hard-to-reach populations and diagnose patients early through expanded testing programs. Timely linkage to medical care is then critical, with research suggesting that patients are less likely to delay initiation of HIV care when they are diagnosed at sites with co-located medical services. ${ }^{44}$

\section{MODELS FOR HIV CARE}

If HIV providers assume more responsibility for increasingly complicated patients (including some with multiple and significant psychosocial needs), and if the overall number of providers remains the same or diminishes, provider availability may not be sufficient to meet patient demand. This suggests a need for new models of HIV care; however, very little has been published about the various current models of care including their development and effectiveness. ${ }^{45}$ One of the more wellrecognized models is the HIVIAIDS-dedicated treatment center, many of which are supported through the Ryan White CARE Act. At the height of the epidemic, such clinics_often hospital-based and/or academically affiliated-began to emerge, offering a range of HIV-focused services including medical, dental, nursing, and pharmacy care; mental health/substance use treatment; nutrition and social work services; and referrals to local case management and service organizations. As such, these centers (unintentionally) became early examples of the "patient-centered medical home." 46 However, a number of HIV centers are now closing or changing focus, moving from providing only specialty care to offering general primary care due to lack of funding and/or changing patient and community needs. ${ }^{47}$ Traditional consultative models (between a referring PCP and off-site specialist) are also used frequently, although patients may or may not always see the specialist directly, depending on visit frequency and travel distance. Such models are especially popular in rural or low HIV prevalence areas. ${ }^{48}$

Alternative models exist that allow patients to stay within their own communities and health systems, while providing PCPs with timely, disease-specific guidance (albeit occasionally at a distance). This is especially useful for HIV, as standards of care tend to be adopted before widespread publication. Such models include: (1) remote consultation services (e.g., the National HIV Telephone Consultation Service $^{49}$ offers 24-hour HIV expert access for individualized case consultation; callers come from varied settings including community clinics, private practices, hospitals and emergency departments, corrections facilities, urgent care centers, and home health agencies); (2) nurse practitioner-physician joint practices (these have been incorporated into health maintenance organizations with large patient volumes); ${ }^{50}$ and (3) integration of HIV care into population-specific (e.g., substance abuse treatment programs) ${ }^{51}$ or community- and primary care-based 
clinics where local HIV experts-who may be specialists or HIV-expert generalistsact as on-site consultants and collaborators. ${ }^{52}$

Such collaborative or "shared care" strategies, which can also support values of the patient-centered medical home, offer several advantages: patients maintain the "continuity, trust, and comprehensiveness of an established relationship" with their $\mathrm{PCP}{ }^{53}$ clinicians in community- and primary care-based settings are already familiar with co-morbidities prevalent among HIV-infected populations, and many offer health promotion (e.g., smoking cessation) and chronic disease programs (which may include patient self-management education). Many primary care clinics also utilize advanced access systems to reduce wait times for appointments and improve continuity of care. ${ }^{54}$ For HIV-infected patients in particular, improved access has been associated with better engagement in care and health-related quality of life, ${ }^{5,56}$ more cost-effective health services utilization, ${ }^{57}$ and timelier initiation of antiretroviral therapy. ${ }^{58}$ Collaborative care also offers the potential to "up-skill" nonHIV-expert providers through individual, patient-based education: for example, providers may learn how to better address antiretroviral adherence, recognize HIV treatment failure, and manage serious infection- and therapy-related complications. Finally, community-based care may be appealing to patients who prefer not to access HIV-identified facilities due to fears regarding stigma.

Although the collaborative care example described above involves the incorporation of HIV experts into primary care settings, the reverse model (where generalists are integrated into HIV care centers or specialty practices) is another possibility. In this scenario, the generalist acts as the on-site consultant to provide guidance on non-HIV-specific disease management and other chronic care issues. Although a few of the practice models described above have been successfully implemented in various US communities, the optimal structure of HIV care delivery remains unknown and there is no "one-size-fits-all" model. In addition, most published data on the effectiveness and "real-world" outcomes of HIV treatment (i.e., not from clinical trials) are from hospital-based or academically affiliated HIV centers and large infectious disease practices. ${ }^{59-62}$ Therefore, clinicians, researchers, and health systems must work together to critically examine alternative structures of HIV healthcare delivery and develop mechanisms that support all effective models.

\section{CONCLUSION}

In conclusion, the success of combination antiretroviral therapy has improved survival in patients with HIV, but aging, chronic infection, and therapeutic complications have led to changes in morbidity and mortality and the need for improved primary care delivery and alternative models of HIV care. Moreover, despite the Center for Disease Control and Prevention's call for expanded, routine HIV testing ${ }^{63}$ and stronger follow-up and outreach efforts, this has yet to be carried out on a widespread, population-level basis: large numbers of patients remain unaware of their status and continue to delay care even after diagnosis. Finally, as guidelines shift back to support earlier initiation of antiretroviral therapy, ${ }^{64}$ the overall number of patients needing HIV treatment will likely increase. The number and availability of HIV providers is predicted to diminish in the near future, however, and the subsequent discrepancy between supply and demand will be felt especially in vulnerable and marginalized populations and medically underserved regions where HIV-related disparities are already prevalent. All of these factors 
highlight the important prevention and treatment roles which primary care providers are well-positioned to step into. As the simultaneous "front-line" and "backbone" of healthcare delivery, primary care clinicians may become invaluable collaborators for the restructuring of HIV care in the current disease era. While examples exist of novel HIV programs which have been developed in response to changing needs of a local environment or population, more outcomes researchincluding comparative effectiveness analysis ${ }^{65}$-is needed to evaluate replicable models of health service delivery (and primary care- and community-based HIV programs in particular). Specific research questions include: how is HIV treatment managed and what are the HIV-related treatment and clinical outcomes in various care models? Who manages other chronic co-morbidities and delivers primary care to infected patients, and how? What are the co-morbidity-related outcomes among HIV-infected populations? As these questions are answered, strategies and structures can be refined to successfully deliver effective HIV-specific and comprehensive primary care and help reduce health disparities: HIV/AIDS continues to evolve, and our healthcare systems must reinvent themselves as well.

\section{REFERENCES}

1. Centers for Disease Control and Prevention. HIV/AIDS Surveillance Report, 2007. Vol 19. Atlanta, GA: U.S. Department of Health and Human Services, Centers for Disease Control and Prevention; 2009: pp 6-15.

2. El-Sadr WM, Mayer KH, Hodder SL. AIDS in American-forgotten but not gone. $N$ Engl J Med. 2010; 362: 967-970.

3. Institute of Medicine, Division of Health Manpower and Resources Development. Primary Health Care Defined. In: A Manpower Policy for Primary Health Care, Report of a Study. Washington, D.C.: National Academy Press; 1978: 15-28.

4. Northfelt DW, Hayward RA, Shapiro MF. The Acquired Immunodeficiency Syndrome is a primary care disease. Ann Intern Med. 1988; 109: 773-775.

5. Kitahata MM, Van Rompaey SE, Dillingham PW, et al. Primary care delivery is associated with greater physician experience and improved survival among persons with AIDS. J Gen Inter Med. 2003; 18: 95-103.

6. Justice AC. Prioritizing primary care in HIV: comorbidity, toxicity, and demography. Top HIV Med. 2007; 14: 159-63.

7. Centers for Disease Control and Prevention. HIV prevalence estimates-United States, 2006. MMWR Morb Mortal Wkly Rep. 2008; 57: 1073-1076.

8. Marks G, Crepaz N, Janssen RS. Estimating sexual transmission of HIV from persons aware and unaware that they are infected with the virus in the USA. AIDS. 2006; 20: 1447-1450.

9. Triant VA, Lee H, Hadigan C, Grinspoon SK. Increased acute myocardial infarction rates and cardiovascular risk factors among patients with human immunodeficiency virus disease. J Clin Endocrinol Metab. 2007; 92: 2506-2512.

10. Brown TT, Cole SR, Li X, Kingsley LA, Palella FJ, Riddler SA, et al. Antiretroviral therapy and the prevalence and incidence of diabetes mellitus in the Multicenter AIDS Cohort Study. Arch Intern Med. 2005; 165: 1179-1184.

11. Bergersen BM, Sandvik L, Dunlop O, Birkeland K, Bruun JN. Prevalence of hypertension in HIV-positive patients on highly active antiretroviral therapy (HAART) compared with HAART-naïve and HIV-negative controls: results from a Norwegian study of 721 patients. Eur J Clin Microbiol Infect Dis. 2003; 22: 731-736.

12. Hooshyar D, Hanson DL, Wolfe M, Selik RM, Buskin SE, McNaghten AD. Trends in perimortal conditions and mortality rates among HIV-infected patients. AIDS. 2007; 21: 2093-2100. 
13. Palella FJ Jr, Baker RK, Moorman AC, Chmiel JS, Wood KC, Brooks JT, et al. Mortality in the highly active antiretroviral therapy era: changing causes of death and disease in the HIV outpatient study. J Acquir Immune Defic Syndr. 2006; 43: 27-34.

14. Lewden C, May T, Rosenthal E, et al. ANRS EN19 Mortalité Study Group and Mortavic1. Changes in causes of death among adults infected by HIV between 2000 and 2005; The "Mortalité 2000 and 2005" surveys (ANRS EN19 and Mortavic). J Acquir Immune Defic Syndr. 2008; 48: 590-598.

15. Pitts M, Grierson J, Misson S. Growing older with HIV: a study of health, social and economic circumstances for people living with HIV in Australia over the age of 50 years. AIDS Patient Care STDs. 2005; 19: 460-465.

16. Oursler KK, Goulet JL, Leaf DA, et al. Association of comorbidity with physical disability in older HIV-infected adults. AIDS Patient Care STDs. 2006; 20: 782-791.

17. Kalayjian RC, Landay A, Pollard RB, Taub DD, Gross BH, Francis IR. Clinical Trial Group 5015 Protocol Team, Adult AIDS Clinical Trial Group 5113 Protocol Team. Agerelated immune dysfunction in health and in human immunodeficiency virus (HIV) disease: association of age and HIV infection with naive CD8+ cell depletion, reduced expression of CD28 on CD8+ cells, and reduced thymic volumes. J Infect Dis. 2003; 187: 1924-1933.

18. Onen NF, Agbebi A, Shacham E, Stamm KE, Onen AR, Overton ET. Frailty among HIVinfected persons in an urban outpatient care setting. J Infect. 2009; 59: 346-352.

19. Terzian AS, Holman S, Nathwani N, et al. Women's Interagency HIV Study. Factors associated with preclinical disability and frailty among HIV-infected and HIV-uninfected women in the era of cART. J Womens Health Larchmt. 2009; 18: 1965-1974.

20. Martin CP, Fain MJ, Klotz SA. The older HIV-positive adult: a critical review of the medical literature. Am J Med. 2008; 121: 1032-1037.

21. Mugavero MJ, Castellano C, Edelman D, Hicks C. Late diagnosis of HIV infection: The role of age and sex. Am J Med. 2007; 120: 370-373.

22. Fultz SL, Goulet JL, Weissman S, et al. Differences between infectious diseases-certified physicians and general medicine-certified physicians in the level of comfort with providing primary care to patients. Clin Infect Dis. 2005; 41: 738-743.

23. Duffus WA, Barragan M, Metsch L, et al. Antiretroviral Treatment and Access Studies Study Group. Effect of physician specialty on counseling practices and medical referral patterns among physicians carding for disadvantaged human immunodeficiency virusinfected populations. Clin Infect Dis. 2003; 36: 1577-1584.

24. Sheth AN, Moore RD, Gebo KA. Provision of general and HIV-specific health maintenance in middle aged and older patients in an urban HIV clinic. AIDS Patient Care STDs. 2006; 20: 318-325.

25. Reinhold JP, Moon M, Tenner CT, Poles MA, Bini EJ. Colorectal cancer screening in HIV-infected patients 50 years of age and older: missed opportunities for prevention. Am J Gastroenterol. 2005; 100: 1805-1812.

26. Center for Workforce Studies. The Complexities of Physician Supply and Demand: Projections Through 2025. Association of American Medical Colleges. 2008. http://services.aamc.org/publications/showfile.cfm?file=version122.pdf. Accessed July 1, 2010.

27. The American Academy of HIV Medicine (AAHIVM) and the HIV Medicine Assoication (HIVMA). Averting a Crisis in HIV Care: A Joint Statement of the American Academy of HIV Medicine (AAHIVM) and the HIV Medicine Association (HIVMA) on the HIV Medical Workforce. American Academy of HIV Medicine and HIV Medicine Association. 2009. https://www.hivma.org/Content.aspx?id=4668. Accessed July 1, 2010.

28. Maldonado V. HIV caseload increasing among primary care providers: HealthHIV State of HIV Primary Care survey confirms trend toward "Medical Home" for people living with HIV. HealthHIV. May 12, 2010. http://www.healthhiv.org/modules/info/files/ files_4beafed41e839.pdf. Accessed July 1, 2010. 
29. Laveist TA, Nuru-Jeter A. Is doctor-patient race concordance associated with greater satisfaction with care? J Health Soc Behav. 2002; 43: 296-306.

30. Laveist TA, Nuru-Jeter A, Jones KE. The association of doctor-patient race concordance with health services utilization. J Public Health Policy. 2003; 24: 312-323.

31. Beran MS, Cunningham W, Landon BE, Wilson IB, Wong MD. Clinician gender is more important than gender concordance in quality of HIV care. Gend Med. 2007; 4: 72-84.

32. Reif S, Geonnotti KL, Whetten K. HIV infection and AIDS in the Deep South. Am J Public Health. 2006; 96: 970-973.

33. Hall HI, Li J, McKenna MT. HIV in predominantly rural areas of the United States. $J$ Rural Health. 2005; 21: 233-245.

34. Krawczyk CS, Funkhouser E, Kilby JM, Kaslow RA, Bey AK, Vermund SH. Factors associated with delayed initiation of HIV medical care among infected persons attending a southern HIV/AIDS clinic. S Med J. 2006; 99: 472-481.

35. Simon PA, Hu DJ, Diaz T, Kerndt PR. Income and AIDS rates in Los Angeles County. AIDS. 1995; 9: 281-284.

36. Peterman TA, Lindsey CA, Selik RM. This place is killing me: a comparison of counties where the incidence rates of AIDS increased the most and the least. J Infect Dis. 2005; 191(Suppl 1): S123-S126.

37. McFarland W, Chen S, Hsu L, Schwarcz S, Katz M. Low socioeconomic status is associated with a higher rate of death in the era of highly active antiretroviral therapy, San Francisco. J Acquir Immune Defic Syndr. 2003; 33: 96-103.

38. Cunningham WE, Hays RD, Duan N, et al. The effect of socioeconomic status on the survival of people receiving care for HIV infection in the United States. J Health Care Poor Underserved. 2005; 16: 655-676.

39. Lillie-Blanton M, Stone VE, Snow Jones A, et al. Association of race, substance abuse, and health insurance coverage with use of highly active antiretroviral therapy among HIV-infected women, 2005. Am J Public Health. 2010 Aug; 100(8): 1493-1499.

40. Turner BJ, Cunningham WE, Duan N, et al. Delayed medical care after diagnosis in a US national probability sample of persons infected with human immunodeficiency virus. Arch Intern Med. 2000; 160: 2614-2622.

41. Samet JH, Freedberg KA, Stein MD, et al. Trillion viral delay: time from testing positive for HIV to presentation for primary care. Arch Intern Med. 1998; 158: 734740.

42. Levine RS, Briggs NC, Kilbourne BS, et al. Black-White mortality from HIV in the United States before and after introduction of highly active antiretroviral therapy in 1996. Am J Public Health. 2007; 97: 1692-1884.

43. Kidder DP, Wolitski RJ, Campsmith ML, Nakamura GV. Health status, health care use, medication use, and medication adherence among homeless and housed people living with HIV/AIDS. Am J Public Health. 2007; 97: 2238-2245.

44. Torian LV, Wiewel EW, Liu K-L, Sackoff JE, Frieden TR. Risk factors for delayed initiation of medical care after diagnosis of Human Immunodeficiency Virus. Arch Intern Med. 2008; 168(11): 1181-1187.

45. Steering Committee of the HIV Innovative Model of Care Initiative, Introduction to the HIV Service Delivery Models and the Steering Committee. The Measurement Group Website. 2005. http://www.themeasurementgroup.com/publications/reports/year2/ chapter_1.htm. Accessed July 1, 2010.

46. Saag MS. Ryan White: An Unintentional Home Builder. AIDS Read. 2009; 19: 166-168.

47. Baah M. As treatment for HIV/AIDS changes, so does role for specialized clinics. Health infoZine. June 4, 2009. http://www.infozine.com/news/stories/op/storiesView/sid/36108/. Accessed July 1, 2010.

48. Mainous AG, Noble RC, Neill RA, Matheny SC. Illustrations and implications of current models of HIV health service provision in rural areas. AIDS Patient Care STDs. 1997; 1: $25-28$. 
49. Goldschmidt RH, Graves DW. The National HIV Telephone Consultation Service (Warmline): a clinical resource for physicians caring for African-Americans. J Natl Med Assoc. 2003; 95: 8S-11S.

50. Sanders P, Lehman L. Nurse practitioner-physician joint practice model for HIV care. Eighth International Conference on AIDS. Amsterdam, The Netherlands. July 19-24, 1992. Abstract no. PuB 7497.

51. Selwyn PA, Budner NS, Wasserman WC, Arno PS. Utilization of on-site primary care services by HIV-seropositive and seronegative drug users in a methadone maintenance program. Public Health Rep. 1993; 108: 492-500.

52. Chu C, Umanski G, Blank A, Beil R, Grossberg R, Selwyn P. Community-based HIV primary care in the Bronx: Patient characteristics and treatment outcomes. Annual Meeting and Exposition, American Public Health Association. Philadelphia, PA. November 7-11, 2009. Abstract no. 205697.

53. Hecht FM, Wilson IB, Wu AW, Cook RL, SGIM AIDS Task Force. Optimizing care for persons with HIV infection. Ann Intern Med. 1999; 131: 136-143.

54. Murray M, Bodenheimer T, Rittenhouse D, Grumbach K. Improving timely access to primary care: case studies in the Advanced Access model. JAMA. 2003; 289: 1042-1046.

55. Mugavero MJ, Lin HY, Allison JJ, et al. Failure to establish HIV care: characterizing the "no show" phenomenon. Clin Infect Dis. 2007; 45: 127-130.

56. Cunningham WE, Hays RD, Williams KW, Beck KC, Dixon WJ, Shapiro MF. Access to medical care and health-related quality of life for low-income persons with symptomatic human immunodeficiency virus. Med Care. 1995; 33: 739-754.

57. Cunningham WE, Mosen DM, Hays RD, Andersen RM, Shapiro MF. Access to communitybased medical services and number of hospitalizations among patients with HIV disease: are they related? J Acquir Immune Defic Syndr Hum Retrovirol. 1996; 13: 327-335.

58. Ulett KB, Willig JH, Lin HY, et al. The therapeutic implications of timely linkage and early retention in HIV care. AIDS Patient Care STDs. 2009; 23: 41-49.

59. Smith D. The HIV Epidemiology Research Study, HIV Outpatient Study, and the Spectrum of Disease Studies. J Acquir Immune Defic Syndr Hum Retrovirol. 1998; 17 (Suppl 1): S17-S19.

60. Moorman AC, Holmberg SD, Marlowe SI, et al. Changing conditions and treatments in a dynamic cohort of ambulatory HIV patients: The HIV Outpatient Study (HOPS). Ann Epidemiol. 1999; 9: 349-357.

61. Landon BE, Wilson IB, Shapiro M, Bozzette S, Cleary P, Association for Health Services Research. Providers of HIV Care. Results from the Health Costs and Services Utilization Study (HCSUS). Abstr Book Assoc Health Serv Res Meet. 1999; 16: 135.

62. Ryan White Medical Providers Coalition. http://www.hivma.org/Content.aspx?id=11236. Accessed July 1, 2010.

63. Centers for Disease Control and Prevention. Revised recommendations for HIV testing of adults, adolescents, and pregnant women in health-care settings. MMWR Morb Mortal Wkly Rep. 2006; 55: 1-17.

64. Panel on Antiretroviral Guidelines for Adults and Adolescents. Guidelines for the use of antiretroviral agents in HIV-1-infected adults and adolescents. Department of Health and Human Services. December 1, 2009; 1-161. http://www.aidsinfo.nih.gov/ContentFiles/ AdultandAdolescentGL.pdf. Accessed July 1, 2010.

65. Comparative Effectiveness Research Funding. http://www.hhs.gov/recovery/programs/cer/ index.html. Accessed July 1, 2010. 